\title{
GROUND-BASED AND SATELLITE OPTICAL INVESTIGATION OF THE ATMOSPHERE AND SURFACE OF ANTARCTICA
}

\author{
Aleksey Malinka $^{1}$ *, Luc Blarel ${ }^{2}$, Ludmila Chaikovskaya ${ }^{1}$, Anatoli Chaikovsky ${ }^{1}$, Natalia Denishchik- \\ Nelubina ${ }^{1}$, Sergei Denisov ${ }^{1}$, Vladimir Dick ${ }^{1}$, Anton Fedaranka ${ }^{1}$, Philippe Goloub ${ }^{2}$, Iosif Katsev ${ }^{1}$, \\ Michail Korol $^{1}$, Aleksandr Lapyonok ${ }^{2}$, Thierr Podvin ${ }^{2}$, Alexander Prikhach ${ }^{1}$, Vadim Svidinsky ${ }^{1}$, \\ Eleonora Zege ${ }^{1}$ \\ ${ }^{1}$ Institute of Physics, National Academy of Sciences, Belarus, *mal@light.basnet.by \\ ${ }^{2}$ Laboratoire d'Optique Atmosphérique, Universite de Lille, France
}

\begin{abstract}
This presentation contains the results of the 10year research of Belarusian Antarctic expeditions. The set of instruments consists of a lidar, an albedometer, and a scanning sky radiometer CIMEL. Besides, the data from satellite radiometer MODIS were used to characterize the snow cover. The works focus on the study of aerosol, cloud and snow characteristics in the Antarctic, and their links with the long range transport of atmospheric pollutants and climate changes.
\end{abstract}

\section{INTRODUCTION}

Recent knowledge on the Earth climate formation undoubtedly shows that Antarctica is one of the key points in the global climate. The polar caps, especially the ice cap in Antarctica that is covered with a snow blanket all-the-year-round, play a key role in the Earth radiation budget. The pollution of snow, e.g., from industrial sources, drastically affects the snow radiation regime and glaciers melting. So, environmental monitoring in Antarctica becomes a global challenge. It's being carried out by the world community, in compliance with the provisions of the international conventions.

Since 2006, in the frame of the Belarusian State Program, the scientific team of the National Academy of Sciences of Belarus has been developing the equipment for monitoring the Antarctic environment, the methods and algorithms for processing satellite and groundbased measurement data, has been performing regular ground-based observations at the Belarus station Mount Vechernyaya (67.66S, 46.16E) and at the Russian stations Molodezhnaya (67.67S, 45.85E) and Progress (69.38S, 76.38E).
The present paper summarizes results of the 10year research of the Belarusian Antarctic Expedition [1].

\section{EQUIPMENT}

Nowadays, three types of the ground-based measurements have been implemented at Mount Vechernyaya: spectral radiometric measurements of the snow surface parameters, multi-wavelength lidar observations of the vertical structure of aerosols and clouds, and sun-radiometric measurements of the column aerosol characteristics.

\subsection{Spectral albedometer $A S-A$}

The spectral albedometer $A S-A$ provides measurements of the spectral reflection of different types of the Earth surface. The albedometer measures both incident and reflected radiation fluxes. $A S-A$ has an operating range of $350-1000 \mathrm{~nm}$.

\subsection{Multi-wavelength radiometer CIMEL}

The multi-wavelength scanning sun/skyradiometer CE-318N (CIMEL) is the basic instrument in the global radiometric network AERONET [2]. It registers two types of radiation: the direct solar (at 340, 380, 440, 500, 670, 940, and $1020 \mathrm{~nm}$ ) and sky-scattered (at 440, 670, 870, and $1020 \mathrm{~nm}$ ) radiation in the principle solar plane and in the almucantar.

Data processing results in retrieval of the aerosol parameters averaged over an atmospheric layer: the aerosol optical thickness (AOT), the Angström exponent, the water vapor content, the aerosol particles size distribution, the refractive index (its real and imaginary parts), and the scattering phase function [3]. The obtained observation data are accessible online (http://aeronet.gsfc.nasa.gov/). 


\subsection{Lidars}

The multi-wavelength lidars provide measurements of the altitude distributions of the aerosol and cloud optical parameters. Up to now, two lidars have been developed for the Antarctic research: the mobile two-wavelength (532 and $1064 \mathrm{~nm})$ lidar and the stationary multiwavelength polarization Raman lidar. The mobile lightweight lidar was designed to operate on open ground. The multi-wavelength polarization Raman lidar provides measurements of the 355 and $1064 \mathrm{~nm}$ backscatter signals, the cross and parallel polarized components at $532 \mathrm{~nm}$, and the Raman signals from atmospheric nitrogen and water vapor in the UV and visible spectral range.

\section{TECHNIQUES}

Parameters of the atmospheric aerosol and Earth surface are retrieved from the data of combined multisensory experiments, including the groundbased and satellite, the radiometric and lidar observations.

\subsection{LIRIC}

Algorithm LIRIC [4] was developed for processing the data of co-located and simultaneous lidar and radiometer soundings (LRS) at the EARLINET and AERONET network stations. It provides sequential inversion of the combined lidar and radiometric data.

The LRS-technique was evolved to retrieve the aerosol mode concentration profiles from the collocated space (lidar CALIOP http://wwwcalipso.larc.nasa.gov/) and ground-based (AERONET) data. The employment of the lidar satellite information has appreciably extended both the area of investigation and the number of potential users.

\subsection{SGSR}

Satellite remote sensing is an important tool for snow cover monitoring, especially over difficultto-access polar regions. However, as a snow pack is a medium with strong multiple scattering by irregularly shaped grains, the classical approaches cannot be applied in algorithms to process the satellite data. An algorithm that takes these features of snow into account has been developed by the team of the Institute of Physics [5]. The
Snow Grain Size and Rocks (SGSR) algorithm takes the signals in the channels of the satellite radiometer MODIS (http://modis.gsfc.nasa.gov/) as an input and gives the maps of the effective snow grain size and the fraction of rocks as an output.

\section{RESULTS}

\subsection{Column aerosol parameters}

Since 2008, the seasonal radiometric observations have been carried out at the AERONET station Vechernyaya and Progress in a coastal region of Antarctica. A specific feature of the Antarctic aerosol is the small concentration of suspended particles and, consequently, the small values of the aerosol optical thickness (AOT).

Figure 1 shows the seasonally averaged spectra of AOT retrieved from the direct solar light measurements. Values of AOT are quite small: $0.02-0.03$ for $\lambda=500 \mathrm{~nm}$. In the IR range, the AOT values fall down to 0.01 and less.

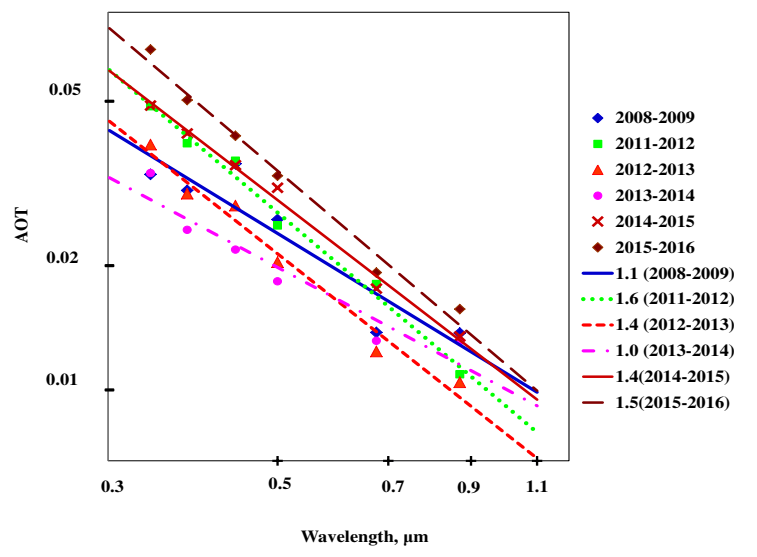

Figure 1 Spectra of AOT in Antarctic coastal zone

Average parameters of aerosol size distributions for the Antarctic coastal zone and the continental region in the Northern Hemisphere (Minsk, Belarus) are compared in Table 1. The column concentration of aerosol particles is considerably less and the content of the coarse particle mode is relatively small in the Antarctic costal region.

Table 1 Columnar concentrations of the aerosol modes

\begin{tabular}{|l|l|l|}
\hline & $\begin{array}{l}\text { Antarctic } \\
\text { coast }\end{array}$ & $\begin{array}{l}\text { Minsk, } \\
\text { Belarus }\end{array}$ \\
\hline Total content of aerosol, $\mu \mathrm{m}$ & 0.0045 & 0.059 \\
\hline Fine/course mode, $\%$ & $82 / 18$ & $54 / 46$ \\
\hline
\end{tabular}




\subsection{Aerosol vertical distribution}

Information about the aerosol vertical structure is obtained from the lidar measurements. The measurements have been carried out at the Mount Vechernyaya station. As the aerosol scattering is very small, as compared to the Rayleigh one, the wavelength of $1064 \mathrm{~nm}$ was used to characterize the aerosol layer stratification (Figure 2).

The LRS-experiment that used both the groundbased and satellite lidar measurements, in addition to the CIMEL data, was made for sounding the vertical structure of aerosol at the coastal zone of Antarctica. Some results are presented in Figure 3. The ground-based lidar measurements were made at 15:00 UTC, December 23, 2012 (67.66S, 46.16E). The aerosol layer with the dominant fine particle mode is detected at the height $3-5.5 \mathrm{~km}$.

Because of clouds in the coastal part of satellite trajectory the CALIOP data were taken from the sector 70.165S, 59.182E - 66.275S, 54.502E, 11:21 UTC, December 23, 2012 which passes over the continental region of Antarctica with the height above sea level $1-3.5 \mathrm{~km}$.

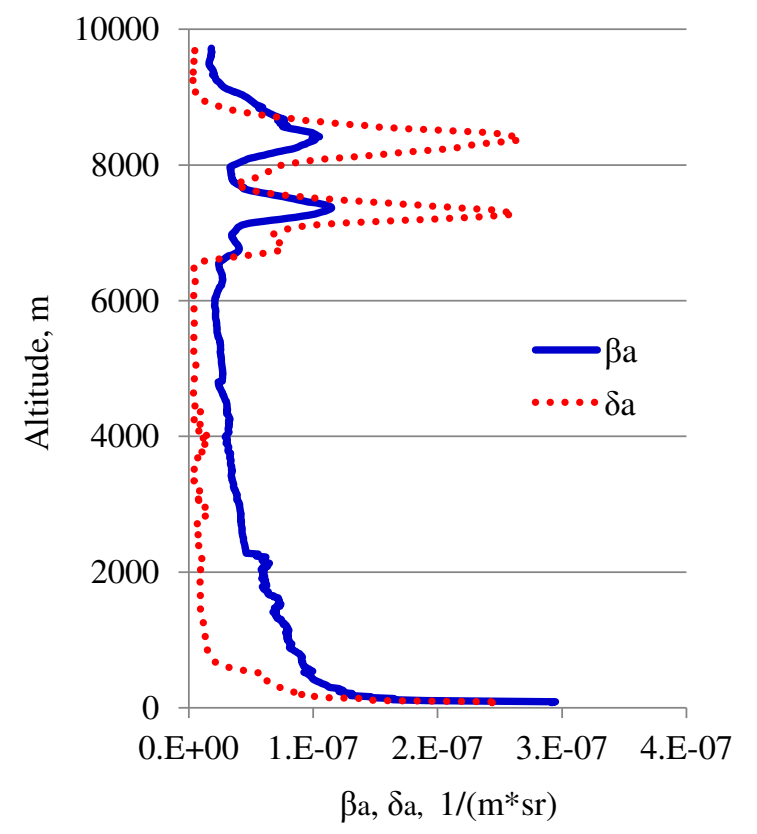

Figure 2 Vertical profile of the backscattering coefficient $\beta_{a}$ and its standard deviation $\delta_{a}$ at $1064 \mathrm{~nm}$ (Mount Vechernyaya, 2014 - 2015)

The retrieval of aerosol characteristics from CALIOP data was carried out under the assumption that the characteristics of the fine and coarse fractions of the aerosol model were identical to parameters determined from radiometric measurements at the Mount Vechernyaya station. Moreover, 30\% deviations of the total content of aerosol fractions in the atmospheric layer from their values at the Mount Vechernyaya station were allowed. The results of the retrieval are shown in Fig. 3. The horizontal lines represent the uncertainty of the fraction concentrations calculated under the assumptions made.

The additional information about the geophysical processes was taken from the results of modeling of the air-mass back trajectories HYSPLIT [6] and from the fire map of the South African region provided by FIRMS, NASA [7].

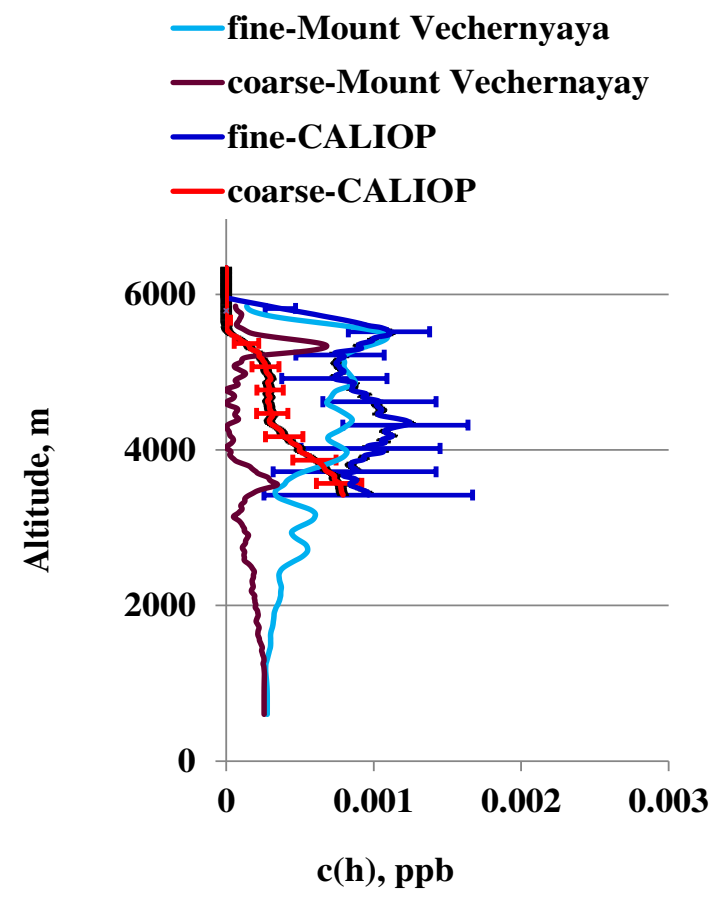

Figure 3 Profiles of concentration of the fine and coarse aerosol particles retrieved from the ground-based lidar and CALIOP data

\subsection{Snow microphysical characteristics from satellite data}

Figure 3 presents the example of the snow grain size and the rock fraction distributions in the region of Vechernyaya retrieved from the MODIS data. The seasonal series of such maps were 
calculated to study the changes of snow characteristics in the Vechernyaya region. In particular, the phenomenon of a sudden decrease of the snow grain size (down to $50-100 \mu \mathrm{m}$ ) after a snowfall event was clearly observed. Between snowfalls the grain size slowly increases to 200$300 \mu \mathrm{m}$, due to the grain growth induced by the snow metamorphism.

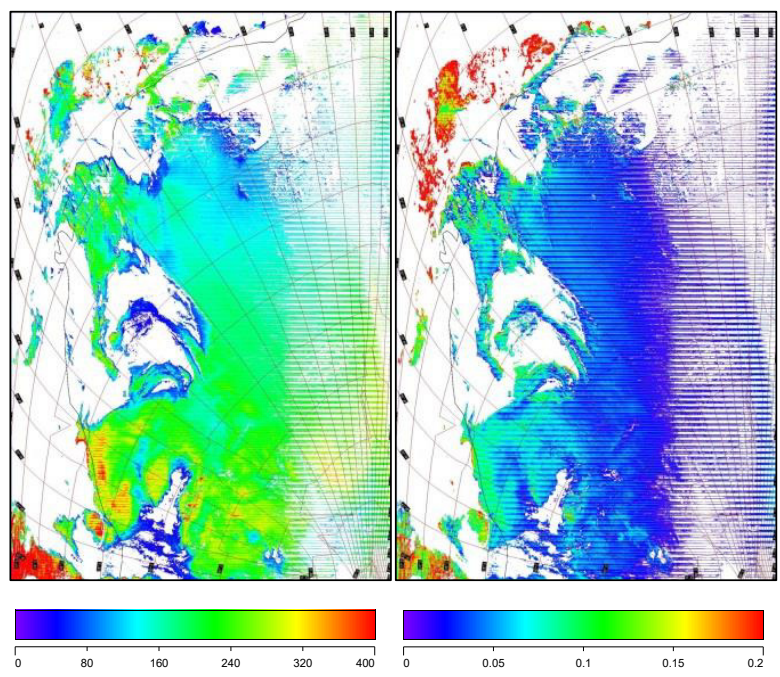

Figure 3 Map of the snow grain size (left, the scale is in micrometers) and rock fraction (right) retrieved from the MODIS-Terra data (January 01, 2015, MOD021KM.A2015001.0755.006.2015002145822.hdf)

\subsection{Field measurements of the surface albedo spectra}

Field measurements of the surface reflection spectra in the region of the Vechernyaya station were aimed at gathering the database of the surface reflectance spectra.

\section{CONCLUSIONS}

The technique of combined ground-based and satellite remote sensing creates the methodological basis for our investigations of the atmospheric aerosol and Earth surface in the Antarctic. The employment of the satellite information allows one to extend the region of investigation. The joint measurements with the different experimental techniques, as well as the special inversion algorithms for processing combined data, aim at obtaining supplementary information about the atmosphere and surface properties, as against the results of independent measurements (the so called synergetic effect).

\section{ACKNOWLEDGEMENTS}

The investigation was supported by: the State Program of Polar Research of Belarus, the EU research and innovation Programme Horizon2020 (ACTRIS-2, grant agreement no. 654109), and the Belarusian Republican Foundation for Fundamental, Research Agreement No. F15SB023. We acknowledge the NASA/GSFC/Earth Science Data and Information System (ESDIS), the NOAA Air Resources Laboratory (ARL), and all the scientists, engineers, and technicians from Belarus, Russia and France, thanks to whom this study became possible.

\section{References}

[1] Chaikovsky, A.P., et al., 2016: Optical studies of the atmosphere and surface in Antarctic, Belarus in Antarctic: on the $10^{\text {th }}$ anniversary of the beginning of scientific and expeditional research, acad. V.F. Loginov ed., Belaruskaya navuka, Minsk, 50-101.

[2] Holben, B.N., et al., 1998: AERONET-A federated instrument network and data archive for aerosol characterization, Rem. Sens. of Env. 66, 1-16.

[3] Dubovik, O., and King, M., 2000, :A Flexible Inversion Algorithm for Retrieval of Aerosol Optical Properties from Sun and Sky Radiance Measurements, J. Geophys. Res. 105 (D16), 20673-20696.

[4] Chaikovsky, A., et al., 2016: Lidar-Radiometer Inversion Code (LIRIC) for the retrieval of vertical aerosol properties from combined lidar/radiometer data: development and distribution in EARLINET, Atmos. Meas. Tech., 9 (3), 1181-1205.

[5] Zege, E.P., et al., 2011: Algorithm for retrieval of the effective snow grain size and pollution amount from satellite measurements, Rem. Sens. of Env. 115 (10), 2674-2685.

[6] Stein, A.F., Draxler, R.R, Rolph, G.D., Stunder, B.J.B., Cohen, M.D., and Ngan, F., 2015: NOAA's HYSPLIT atmospheric transport and dispersion modeling system, Bull. Amer. Meteor. Soc. 96, 2059-2077.

[7] Fire Information for Resource Management System (FIRMS),

https://earthdata.nasa.gov/earth-observationdata/near-real-time/firms (September 2016). 